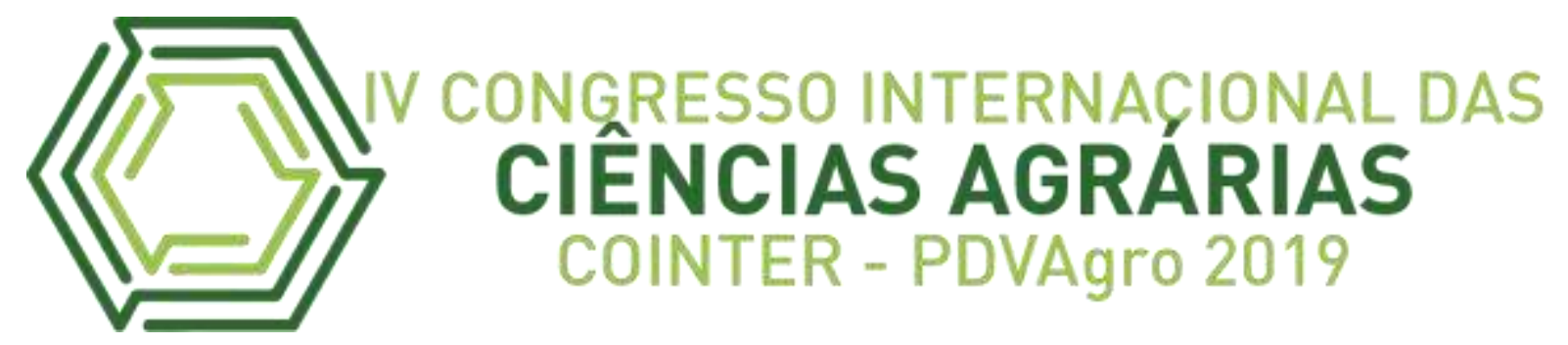

\title{
VARIABILIDADE DE MICRONUTRIENTES EM NEOSSOLOS DE ORIGEM ARENÍTICA NA SOB MATA NATIVA
}

\author{
Apresentação: Pôster \\ DOI: https://doi.org/10.31692/2526-7701.IVCOINTERPDVAgro.2019.0174
}

\section{Introdução}

Os solos do sul do Piauí são de grande importância para o Brasil, pois apresentam grande potencial agrícola, havendo uma predominância de solos leves, dentre eles, estão os Neossolos que apresentam pequenas quantidades de nutrientes essenciais para o crescimento das plantas. Marques et al. (2004) relataram que os solos do Cerrado apresentam teores totais de alguns micronutrientes, como o $\mathrm{Cu}, \mathrm{Zn}$ e $\mathrm{Mn}$, equivalentes à metade do valor da média mundial, atribuindo esses valores ao intenso processo de intemperismo ocorrido nessa região.

A variabilidade espacial dos micronutrientes e também de outras características físicas e químicas do solo determina a intensidade e a forma de amostragem para compor amostras representativas desse solo (SILVEIRA \& CUNHA, 2002).

Esse trabalho teve por objetivo avaliar a variação de atributos químicos e eletroquímicos em dois Neossolos sob mata nativa no cerrado piauiense.

\section{Fundamentação Teórica}

A atuação dos processos e fatores de formação dos solos condicionaram uma variação nas características químicas, tornando imprescindível o conhecimento e o entendimento dessas diversidades químicas.

\section{Metodologia}

A área de estudo está localizada na microrregião de Bertolínia-PI no sudoeste piauiense (Figura 1.), pertencentes ao Bioma Cerrado. Os solos dessa região foram formados na era Paleozoica, apresentando variedades de unidades climáticas e litologias, contudo, a maior parte das formações que ocorrem nestas microrregiões possui o Arenito como material originário principal, onde foram coletadas amostras em dois Latossolos, sendo um Neossolo Fúlvico (P1) e Latossolo Litólico (P2). 
Figura 1. Mapa da área de estudo na microrregião de Bertolínia-PI no sudoeste piauiense.

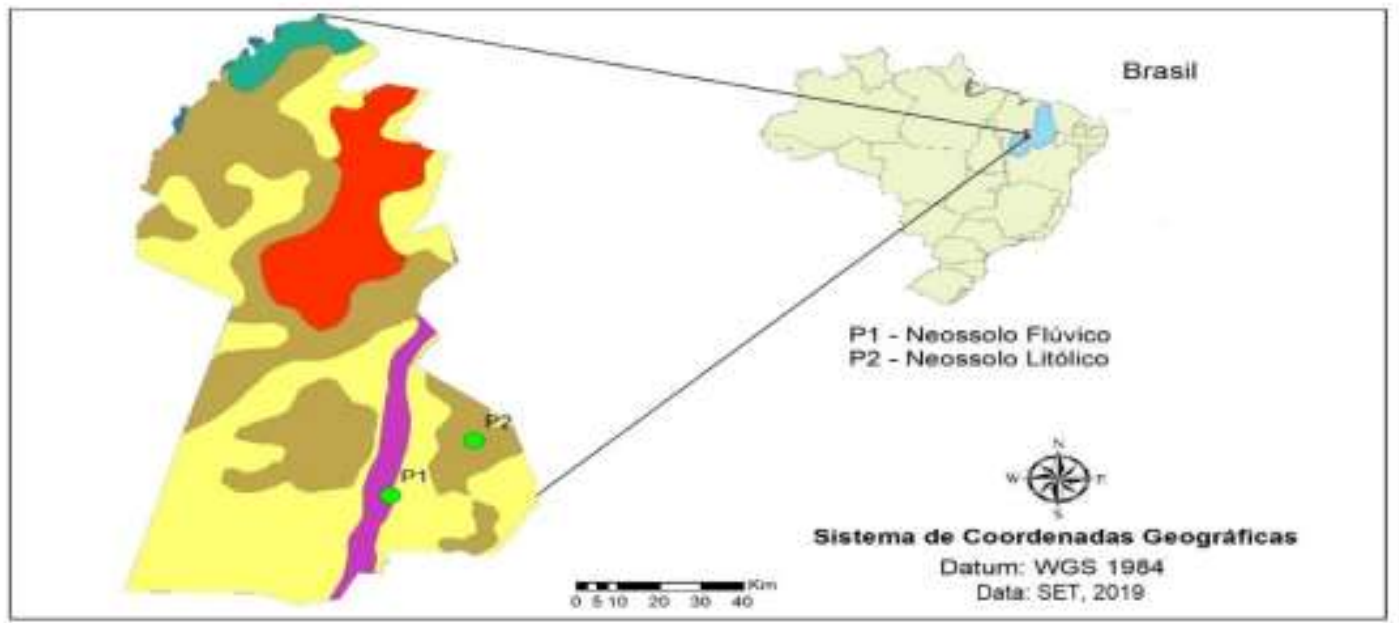

Todo o processo de abertura do perfil, descrição morfológica e amostragem de solo foi realizada seguindo os critérios descritos por Santos et al. (2005).

As amostras foram secas ao ar, destorroadas e passadas em peneira de aço inox com malha de 2,00 mm (TFSA) e submetidas as análises químicas de $\mathrm{pH}$ (água e $\mathrm{KCl}$ ), cobre $(\mathrm{Cu}$ ), ferro (Fe), manganês (Mn) e Zinco ( $\mathrm{Zn})$ e calculado os valores equivalentes a carga líquida $(\Delta \mathrm{pH})$ seguindo as metodologias descritas por Teixeira et al. (2017).

\section{Resultados e Discussões}

Observou-se que ambos perfis apresentaram acidez de neutro a alcalino, porém com carga líquida negativa, além de apresentar uma ampla distribuição na quantidade de micronutrientes no decorrer dos perfis dos solos. No Neossolo Fúlvico observa-se que os maiores teores de todos os micronutrientes estudados estão situados nas camadas mais superficiais, com exceção do Mn que apresenta maior variação entre as camadas (Tabela 1), esse comportamento está atrelado aos processos de formação desse solo, uma vez que são formados a partir da deposição de material oriundo de diferentes áreas.

Já no Neossolo Litólico as maiores concentrações de micronutrientes estudados estão próximo ao material de origem, mesmo que seja em pequenas concentrações, mostrando a influência do arenito sobre as características químicas desse solo. 
Tabela 1. Analise química de potencial hidrogeniônico e micronutrientes em Neossolos do Cerrado piauiense sob mata nativa.

\begin{tabular}{|c|c|c|c|c|c|c|c|}
\hline \multirow{2}{*}{ Horizonte } & \multicolumn{2}{|c|}{--- pH --- } & \multirow{2}{*}{$\Delta \mathrm{pH}$} & $\mathrm{Cu}$ & $\mathrm{Fe}$ & $\mathrm{Mn}$ & $\mathrm{Zn}$ \\
\hline & $\mathrm{H}_{2} \mathrm{O}$ & $\mathrm{KCl}$ & & \multicolumn{4}{|c|}{$\mathrm{mg} \cdot \mathrm{dm}^{-3}$} \\
\hline \multicolumn{8}{|c|}{ Neossolo Fúlvico } \\
\hline $\mathrm{A}$ & 6,34 & 5,33 & $-1,01$ & 2,03 & 110,1 & 31,17 & 4,23 \\
\hline $2 \mathrm{C} 1$ & 5,64 & 4,63 & $-1,01$ & 2,43 & 129,17 & 27,43 & 2,74 \\
\hline $3 \mathrm{C} 3$ & 5,67 & 4,71 & $-0,96$ & 2,15 & 157,06 & 17,07 & 2,26 \\
\hline $4 \mathrm{C} 3$ & 6,26 & 5,23 & $-1,03$ & 1,92 & 153,62 & 34,15 & 3,9 \\
\hline $5 \mathrm{C} 4$ & 8,04 & 6,49 & $-1,55$ & 1,93 & 59,82 & 17,41 & 2,63 \\
\hline $6 \mathrm{C} 5$ & 8,57 & 6,96 & $-1,61$ & 2,14 & 91,52 & 18,88 & 2,93 \\
\hline 7C6 & 8,71 & 7,30 & $-1,41$ & 1,48 & 91,39 & 55,65 & 1,02 \\
\hline $8 \mathrm{C} 7$ & 8,50 & 7,11 & $-1,39$ & 1,65 & 75,36 & 15,02 & 1,32 \\
\hline $9 \mathrm{C} 8$ & 8,42 & 6,93 & $-1,49$ & 1,71 & 72,76 & 13,56 & 1,43 \\
\hline $10 \mathrm{C} 9$ & 8,11 & 6,65 & $-1,46$ & 1,76 & 74,92 & 12,49 & 1,36 \\
\hline $11 \mathrm{C} 10$ & 7,88 & 6,60 & $-1,28$ & 1,43 & 43,51 & 73,98 & 3,12 \\
\hline \multicolumn{8}{|c|}{ Neossolo Litólico } \\
\hline A & 6,98 & 5,90 & $-1,08$ & 1,54 & 2,13 & 86,8 & 0,76 \\
\hline $\mathrm{CR}$ & 6,82 & 5,33 & $-1,49$ & 1,3 & 25,41 & 11,8 & 0,34 \\
\hline
\end{tabular}

\section{Conclusões}

O Neossolo Litólico apresentou mais características com o material de origem.

O Neossolo Fúlvico apresentou maiores quantidades de micronutrientes nas câmaras mais superficiais.

\section{Agradecimentos}

Coordenação de Aperfeiçoamento de Pessoal de Nível Superior - Capes.

\section{Referências}

MARQUES J.J.; SCHULZE, D.G.; CURI, N.; MERTZMAN, S.A. Trace element geochemistry in Brazilian Cerrado soils. Geoderma, v.121, p.31-43, 2004.

OLIVEIRA, I. P. de; KLUTHCOUSKI, J.; BALBINO, L. C.; BUSO, L. H.; YOKOYAMA, L. P.; MAGNABOSCO, C. de U.; SCARPATI, M. T. V. Sistema Barreirão: emprego de micronutrientes na recuperação de pastagens. Santo Antônio de Goiás: Embrapa-CNPAF, 1998. 36 p. (Circular Técnica, 30).

SANTOS, R. D. et al. LHC Manual de descrição e coleta de solo no campo. (Revisada e Ampliada). Sociedade Brasileira de Ciência do Solo/Centro Nacional de Pesquisa de Solos (EMBRAPA): Viçosa, 2005. 
SILVEIRA, P. M. Da; CUNHA, A A. Variabilidade de micronutrientes, matéria orgânica e argila de um Latossolo submetido a sistemas de preparo. Pesquisa Agropecuária Brasileira, v. 37, n. 9, p. 1325-1332, 2002.

SOUSA, DMG de; LOBATO, Edson. Cerrado: correção do solo e adubação. Planaltina: Embrapa Cerrados, 2004.

TEIXEIRA, P. C. et al. Manual de métodos de análise de solos. 3. Ed. Embrapa Solos, Brasília, BR, 2017. 